\title{
Management Of Depressed Skull Fracture
}

\author{
Liaqat Ali ${ }^{1}$, Adnan Badar ${ }^{2}$
}

\begin{abstract}
Background: Head injury is the most serious problem all around the world. Over the last 200 years both surgical and conservative management have been evolved. Chronological surgical management yields better outcome by decreasing mortality and morbidity. Wound debridement, repair of dural defect and closure of wound are standard principles in management.

Objective: To study the outcomes of surgical management of depressed skull fracture.

Material and methods: This study was conducted in Shifa Medical center from $1^{\text {st }}$ June 2016 to $30^{\text {th }}$ June 2019 . Clinical features cause, and computerized tomography (CT) pictures were compiled in proforma. Whenever depressed fracture size exceeded than $5 \mathrm{~mm}$, cosmetically disfiguring and fracture over the sinus were operated. All the patients were followed for six months.

Results: Total of 60 patients were included 42 patients $(70 \%)$ were male and $18(30 \%)$ were female. Pediatric population was major contributor 36 out of 60 patients (ratio60\%). 56 patients (93.33\%)operated, 4 patients (6.67\%) were treated conservatively. These 4 patients $(6.67 \%)$ had severe head injury and were put on ventilator 32 patients $(53.3 \%)$ fully recovered, 12 patients $(20 \%)$ had moderate disability, 8 patients $(13 \%)$ had severe disability and 3 patients $(4.8 \%)$ pass away in this study.

Conclusion: It was found that, depressed skull fracture was mostly common in children. Usage of antibiotic and anticonvulsants had effective results in term of preventing infection and epilepsy during perioperative period. Initial stage surgical treatment is exceptionally required where size of fracture exceed $5 \mathrm{~mm}$. Outcome depended upon the sternness of injury and existence of associated intra cerebral lesion.
\end{abstract}

Key words: surgical management, depressed skull fracture (DSF) and CSF leakage.

This article may be cited as: Ali L, Badar A.

Management of Depressed Skull Fracture. J Saidu Med Coll Swat 2021;11(1):30-33

\section{INTRODUCTION}

The most serious problem worldwide is head trauma. ${ }^{1}$ Last 200 years of development in field of surgical approaches to open and closed depressed skull fractures, but primary bone or regional fragment replacement (after usage and treatment with antiseptics) is the most consistent option. ${ }^{2,3}$ Chronologically surgical management delivers best outcomes by decreasing mortality and morbidity. ${ }^{4}$ To describe the clinical, sociodemographic and radiological results of findings of patients with depressed skull fractures covering cranial dural sinuses that we have faced impervious institute reports. ${ }^{5}$ When fragment of skull fracture bone is displaced inward for distance equal to or greater the width of calvarias is known as depressed skull fracture. ${ }^{6}$ Skull fracture can occur with or without damage to the brain. It is common in low speed trauma. The principles of management had gone through considerable evaluation in the past few decades both surgical and conservative management were adopted even compound fracture can be manage without operation.

Patients presented with infected depressed fracture, ragged scalp laceration, severely

1. Associate Professor, Anatomy Department, Swat Medical College, Swat. 2.Assistant Professor, Anatomy Department, Swat Medical College, Swat.

Correspondence: Dr. Liaqat Ali (FRCS)

Shifa Medical Centre Saidu Sharif Swat

Email: liaqatnsurgeon@yahoo.com comminuted skull fracture and presence of brain tissue or CSF leakage needs surgical management. Skull fracture associated with laceration is called depressed fracture if it is not simple fracture. ${ }^{8}$ Compound depressed fracture is more clinically important if these are not managed promptly can lead to threatening complications. Wound debridement, repair of dural defect and closure of wound are standard principles and saved patients from cranioplasty. ${ }^{9}$

CT scan is the study of choice for diagnosing of skull fracture (DSF) and associated intracranial lesion. ${ }^{6,10}$ Along with this the depressed fractures above or overlying venous sinuses are left undisturbed to skip hemorrhage. ${ }^{11}$

Depressed skull fracture with the evidence of dural tear and increase in intracranial pressure (ICP) particularly above middle and posterior $3^{\text {rd }}$ of superiorsagittal sinus, should be surgically managed. $^{12}$

Early placement of bone pieces in compound depressed skull fractures don't increase the risk of infection. ${ }^{13}$

Usage of prophylactic antibiotics did not decrease the infection rate. Existence of dural tear was not concerned with a huge risk of post-traumatic epilepsy. $^{14,15}$ 


\section{MATERIALAND METHODS}

This descriptive study was conducted in Shifa Medical Centre Swat form $1^{\text {st }}$ June 2016 to $30^{\text {th }}$ June 2019.

Depressed skull fracture: When fragment of skull fracture bone is displaced inward for distance equal to or greater the width of calvarias is known as depressed skull fracture. ${ }^{6}$

Patients from 1 to 63 years of age presented with skull fracture and consented for surgical intervention, were included in the study.

Patients below 1 year and above 63 years were excluded. Patients not having depressed skull fracture and those who did not give consent were excluded.

CT scan was done in all depressed skull fracture, removal of in driven bone fragments, debridement of wound margins, elevation of depressed skull bone fragment, evacuation of hematoma, repair of Dural tear and initial repair were done in respective patients. ${ }^{13} \mathrm{CT}$ scan was reported by qualified radiologist with 18 years experience. All the patients included in this study were operated by qualified neurosurgeon, who in FRCS (neurosurgery) and having more than 25 years of experience.
All patients received antibiotic and anticonvulsants. These patients were followed up to 7 postoperative days. All patients were followed in OPD at one month, three months and six months intervals. Evaluation of wound infection, fits, CSF leakage and neurological assessment completed in every required visit. All data was recorded on available proforma. The data was analyzed by using SPSS 23.0. The results recorded in text, tables and a pie chart.

\section{RESULTS}

In this study 60 patients were included, 42 patients $(70 \%)$ were male and 18 female $(30 \%)$. Majority of patients were in first decade $33 \%$ and in second decade were $25 \%$ of life. Mostly they were involved in road traffic accident (RTA) 32 patients $(52.33 \%)$, falls were responsible for 16 patients $(26.67 \%)$ physical assault in 12 patients $(20.00 \%)$.

Patients presented with symptoms of headache and vomiting were $70 \%$, loss of consciousness were $33 \%$, bleeding from nose and ear were $40 \%$, CSF leakage $17 \% .70 \%$ were presented with increase intracranial pressure (ICP), 17\% with extradural hematoma, $1.6 \%$ has acute sub duralhematoma and $16 \%$ had underline brain contusions.

Table 1. Details of Cause of Injuries

\begin{tabular}{|c|c|c|c|c|c|c|}
\hline S. No & \multicolumn{2}{|c|}{ Cause of Injury } & \multicolumn{2}{|c|}{ Total No. of Patients } & \multicolumn{2}{|c|}{ Percentage } \\
\hline 1 & \multicolumn{2}{|c|}{ Road Traffic Accident (RTA) } & \multicolumn{2}{|c|}{32} & \multicolumn{2}{|c|}{$53.33 \%$} \\
\hline \multirow[b]{2}{*}{2} & \multirow[b]{2}{*}{ Fall } & Fall from roof top & \multirow[b]{2}{*}{25} & 16 & \multirow[b]{2}{*}{$46.67 \%$} & $26.67 \%$ \\
\hline & & $\begin{array}{l}\text { Fall from physical } \\
\text { assault }\end{array}$ & & 12 & & $20.00 \%$ \\
\hline Total & ----- & --------- & \multicolumn{2}{|c|}{60} & \multicolumn{2}{|c|}{$100 \%$} \\
\hline
\end{tabular}

Table 2. Site of Bone Involvement

\begin{tabular}{|c|c|c|c|}
\hline \multirow{2}{*}{ S.No } & \multirow{2}{*}{ Affected Regions } & \multicolumn{2}{|c|}{ Patients } \\
\cline { 3 - 4 } & Temporal Region & No. of Patients & Percentage \\
\hline $\mathbf{1}$ & Frontal Region & 30 & $50.00 \%$ \\
\hline $\mathbf{2}$ & Parietal Region & 12 & $20.00 \%$ \\
\hline $\mathbf{3}$ & Occipital Region & 10 & $16.67 \%$ \\
\hline $\mathbf{4}$ & Many Regions Involvement & 4 & $06.67 \%$ \\
\hline $\mathbf{5}$ & --------- & 4 & $06.67 \%$ \\
\hline Total & & 60 & $100 \%$ \\
\hline
\end{tabular}

Table 3. Glasgow Comma Scale (GCS) Presentation

\begin{tabular}{|c|c|c|c|}
\hline \multirow{2}{*}{ S.No } & Outcome on Glasgow Comma & \multicolumn{2}{|c|}{ Patients } \\
\cline { 3 - 4 } & Scale (CGS) & No. of Patients & Percentage \\
\hline $\mathbf{1}$ & Fully Recovered & 32 & $53.33 \%$ \\
\hline $\mathbf{2}$ & Moderate Disability & 12 & $20.00 \%$ \\
\hline $\mathbf{3}$ & Sever Disability & 8 & $13.33 \%$ \\
\hline $\mathbf{4}$ & Develop Wound Infection & 8 & $13.33 \%$ \\
\hline Total & ------------ & 60 & $100 \%$ \\
\hline
\end{tabular}


56 patients were operated 4 patient were treated conservatively these 4 patients had severe head injury and were put on ventilator.

Outcome calculated on Glasgow Comma Scale (GCS) scoring system. 32 patients $53.3 \%$ fully recovered. 12 patients $20 \%$ modrate disability 8 patients $13 \%$ had severe disability. 8 patients develop wound infection and were treated with antibiotic but 2 patients develop subdural empyema and were treated surgically. Only 4 patients $6.66 \%$ manage conservatively that were in GCS 3-4 and were on ventilator, 3 patients died and 1 patient alivewith vegetativestate.

\section{DISCUSSION}

In this study total 60 patients were included male were dominant. Head injury is a huge problem in developing countries. It may be lethal in young population. ${ }^{10,13,16}$ Depressed skull fracture is common in majority of head injuries. Both conservative and surgical methods can be adopted for management of these patients depending on cosmetics and functional outcome. In this study majority were children of school going age $1-1033 \%$.Due to road traffic accidents or falls from roof tops. ${ }^{6,14}$ The skull fracture pattern is usually affected by two factors. The first factor is the force of impact. The second factor is the ratio of impact. The ratio of impact even of high energy if dispersed over a large area, as in head injury to an individual wearing a motorcycle helmet often produces no skull fracture, however if the impact is of low energy in small area will often produces skull fractures. ${ }^{20}$

Another study by $Z$ Binders B and E.N.Sayi reported RTA is a cause of depressed fracture in $32 \% .{ }^{15-17}$ In our study the most common sight of depressed skull fracture was parietal bone $36 \%$, temporal bone $28 \%$, frontal bone $24 \%$ and $8 \%$ in occipital region while in report of Miura $F$ K Plage $\mathrm{J} P$ in series fronto parietal bone were involved in $58.8 \% .{ }^{19}$ While AAdelougeShoukumbi shows 50\% frontal and $33.3 \%$ parietal region involvement. While S M Mlay\& E N Sayi reported $36.8 \%$ frontal and $39.5 \%$ parietal region. ${ }^{17}$

Physical examination is difficult due to swelling of wounds. In our study most of the patients presents with Glasgow Comma Scale (GCS) 8-12 while in others study they were 12-15. Glasgow coma Scale were used to observe the outcome in management of skull fracture..$^{21,22}$
A compound depress fracture is neurosurgical emergency because of risk of bacterial infection. In these cases initial surgery was performed. In surgical procedures all foreign bodies were removed, elevation of depressed fracture and repair of Dura matter done.

\section{CONCLUSION}

Young adults and children, male gender was commonly affected. Road traffic accident and falls from heights were common modes of injuries. Antibiotic and anticonvulsant were affective in prevention of epilepsy and infection. If treated promptly most of the cases of compound depress skull fracture revealed good results but outcomes of the depress skull fracture be contingent upon the severity of injury and absence or presence of related intracranial lesion.

\section{REFERENCES}

1. Amir S. Depressed skull fracture: surgical management and outcome. J Med Sci. 2017;25(3):336-9.

2. Stein SC. The evolution of modern treatment for depressed skull fractures. World Neurosurg. 2019;121:186-92.

3. Imran M, Khan AA, Ahmed SI, Ghouri SA, Khan AR, Farooqui MO. Compound depressed fractures. Prof Med J. 2018;25(05):633-8.

4. Ahmad S, Afzal A, Lal Rehman FJ. Impact of depressed skull fracture surgery on outcome of head injury patients. Pakistan J Med Sci. 2018;34(1):13038.

5. Mohamed Mostafa A, El Molla ST, Abdelrahiem HA, Dawood OM. Depressed Skull Fractures Overlying Dural Venous Sinuses: Management Modalities and Review of Literature. Turk Neurosurg. 2019;29(6):856-63.

6. Ali M, Ali L, Roghani IS. Surgical management of depressed skull fracture. J Postgrad Med Inst. 2003;17(1).83-89

7. Miller JD, Murray LS, Teasdale GM. Development of a traumatic intracranial hematoma after a "minor" head injury. Neurosurgery. 1990;27(5):669-73.

8. AZAM F, Khattak A, Alam W. Surgical Management and Outcome of Depressed Skull Fracture. Pakistan J Neurol Surg. 2010;14(1):304-09.

9. Kirkwood JR. Head trauma, in essential of neurosurgery. Churchill living Stone, New York; 1990.

10. Blankenship JB, Chadduck WM, Boop FA. Repair of compound-depressed skull fractures in children with replacement of bone fragments. Pediatr Neurosurg. 1990;16(6):297-300.

11. Prakash A, Harsh V, Gupta U, Kumar J, Kumar A. Depressed fractures of skull: an institutional series of 453 patients and brief review of literature. Asian J Neurosurg. 2018;13(2):222-29.

12. Van Den Heever CM, van der Merwe DJ. Management of depressed skull fractures: Selective conservative management of nonmissile injuries. J Neurosurg. 1989;71(2):186-90. 
13. Wylen EL, Willis BK, Nanda A. Infection rate with replacement of bone fragment in compound depressed skull fractures. Surg Neurol. 1999;51(4):452-7.

14. Al-Haddad SA, Kirollos R. A 5-year study of the outcome of surgically treated depressed skull fractures. Ann R Coll Surg Engl. 2002;84(3):196-201.

15. Richard Kuehl, Andrea Büchler, Andreas F Widmer, Manuel Battegay, Digging Out the EvidenceHow Strong Is the IDSA Recommendation Against Antibiotic Prophylaxis in Basilar Skull Fracture and Cerebrospinal Fluid Leakage?, Clinical Infectious D is e a s e . $2018 ; 66$ ( 8 ): 13191320 , https://doi.org/10.1093/cid/cix984

16. Zbinden B, Kaiser G. Specific aspects of depressed skull fractures in childhood. Zeitschrift für Kinderchirurgie. 1989;44(01):37-42.

17. Mlay SM, Sayi EN. The management of depressed skull fractures in children at Muhimbili Medical Centre, Dar es Salaam, Tanzania. East Afr Med J. 1993;70(5):291-3.

18. Ogunleye AOA, Adeleye AO, Ayodele KH, Usman MO, Shokunbi MT.Arrow injury to the skull base. West Afr J Med. 2004;23(1):946-52.

19. Du Plessis JJ. Depressed skull fracture involving the superior sagittal sinus as a cause of persistent raised intracranial pressure: a case report. J Trauma Acute Care Surg. 1993;34(2):290-2.

20. Thomas LM. Skull fracture in Ramgchay SS, Wilkins W (ed) Neurosurgery New York 1985.

21. Lihai Ren, Dangdang Wang, Xi Liu, Huili Yu, Chengyue Jiang, and Yuanzhi Hu . Influence of Skull Fracture on Traumatic Brain Injury Risk Induced by Blunt Impact Int J Environ Res Public Health. 2020 Apr; 17(7): 2392-99.

22. Barbosa A, Fernandes FAO,Alves de Sousa RJ, Ptak $\mathrm{M}$, Wilhelm J. Computational Modeling of Skull Bone Structures and Simulation of Skull Fractures Using the YEAHM Head Model. Biology (Basel). 2020 Sep 4;9(9):267. doi: 10.3390/biology9090267. PMID: 32899779; PMCID: PMC7566004.
DATA SHARING STATEMENT: The data that support the findings of this study are available on request from the corresponding author. The data are not publicly available due to privacy or ethical restrictions.

CONFLICT OF INTEREST: Authors declare no conflict of interest.

GRANTED SUPPORT AND FINANCIAL DISCLOSURE:
Nil

\section{AUTHOR'S CONTRIBUTION}

Following authors have made substantial contributions to the manuscript as under

Ali L:

Concept and design of study, Collection of data, statistical analysis

Writing of manuscript, critical review of manuscript

Badar A: Analysis and interpretation of data, statistical analysis

Data collection, bibliography

Authors agree to be accountable for all aspects of the work in ensuring that questions related to the accuracy or integrity of any part of the work are appropriately investigated and resolved. 